\section{Engineering Principles Impacting High-tunnel Environments}

\author{
Gene A. Giacomelli ${ }^{1}$
}

AdDitional INDEX wORDs. Controlled environment agriculture, season extension, temporary structure, hoop house

SUMMARY. High tunnels are a special type of greenhouse with primary operational goals of season extension, crop quality improvement, and new crop production opportunities to reach unique markets. From an engineering viewpoint, high tunnels have many of the same design concerns as larger, more complex greenhouses. They capitalize on the greenhouse effect as do all enclosed plant growth structures. However, less automated environmental control systems are required for the desired crop production. Tunnel designs are less complex and less expensive than large high-technology greenhouse ranges, but they must be designed and constructed with the fundamental assurance of structural stability, safety, efficient layout, appropriate environmental control, and effective crop management in mind.

$\mathrm{H}$ igh tunnel crop production systems capitalize on the greenhouse effect and its subsequent microclimate modification. They are part of controlled environment agriculture (CEA) systems for crop production. They can provide daytime air and soil warming during the spring, fall, and winter, and protection from heavy rains, strong winds, and other adverse weather conditions. Many producers in mild winter climates use high tunnels for cool season vegetables. As a production system, they offer dependable and specific crop production goals, including enhanced quality, increased yields, and improved timing, leading to improved product marketability and greater profits. They are labor intensive, even more than field production of vegetable crops. However, they are more than simply field production inside a structure and a cover, even though they typically produce crops that are gown in the soil. Their use can provide locally grown produce, limited or no pesticides use, and reduced transport distance to market. Crops can range from a polyculture of unique mixes of specialty products, or a monoculture of seedling transplants for field production, in, for example,

Department of Agricultural and Biosystems Engineering, The University of Arizona, 1951 E. Roger Road, Tucson, AZ 85719

This is Controlled Environment Agriculture Center (CEAC) Paper \#D-125933-03-08.

This research was supported by CEAC, the Controlled Environment Agriculture Center, College of Agriculture and Life Sciences, The University of Arizona.

${ }^{1}$ Corresponding author. E-mail: giacomel@ag.arizona. edu. lettuce (Lactuca sativa) transplants. They have an important, multifaceted role in the food production industry. Unlike high-technology greenhouses of greater complexity and costs, high tunnels do have significant limitations for controlling the plant environment. They cannot control the root zone and the aerial zone of the plant as well as a greenhouse with climate control systems for heating, cooling, shading, etc. However, they do offer improved crop protection from adverse weather conditions compared with the open field or plasticulture techniques such as row (low) tunnels in the field. For example, the aerial environment is provided with rain and wind shelter, with limited insect exclusion, and with some protection from cold night air temperature. The root-zone environment is provided with a controlled water regime and the potential for nutrient enhancement.

The definition of a high tunnel is a freestanding or gutter-connected covered structure, without heating or electrical power, using passive ventilation for air exchange and cooling, and an irrigation system for crop production. They are modular in design, typically constructed of a curved metal pipe or steel tube frame with input/output from the ends or sides for worker and/or small tractor entry for soil tillage. They are considered temporary agricultural structures in terms of building codes, and can be easily covered each season and uncovered after the last harvest. They can be disassembled to be reconstructed at a different site in subsequent years. However, for a more permanent structure, concrete footings can be used in the construction.

\section{Tunnel design}

High tunnel costs can range from $\$ 3 / \mathrm{ft}^{2}$ for the construction materials for a $30 \times 96-\mathrm{ft}$ structure (Lamont et al., 2002) to $\$ 4.39 / \mathrm{ft}^{2}$ for materials and installation of a $17 \times$ 36-ft structure (Reiss et al., 2004). Typical greenhouse construction costs range from $\$ 50 / \mathrm{m}^{2}\left(\$ 4.65 / \mathrm{ft}^{2}\right)$ for low-technology greenhouses to $\$ 200 / \mathrm{m}^{2}\left(\$ 18.58 / \mathrm{ft}^{2}\right)$ for hightechnology greenhouses, including materials and installation (Costa and Giacomelli, 2005).

The simple high tunnel is a singlespan, "ground-to-ground" (Quonsetshaped) structure that is constructed of a lightweight steel tube frame of 1.5 to 2 inches in diameter. It can also be attached together to form a multispan structure. The continuous curved, arch-shaped roof offers simplicity and strength with affordability to obtain span widths from 14 to $30 \mathrm{ft}$. Additional vertical "legs" can be included on the sidewalls of the "ground-to-ground" design to raise the entire curved roof structure an additional 5 to $6.6 \mathrm{ft}$ above the ground. This can also provide for multiple individual roof spans to be attached as a frame together to create a multispan structure (Fig. 1).

\begin{tabular}{llll}
\hline $\begin{array}{l}\text { Units } \\
\begin{array}{l}\text { To convert U.S. to SI, } \\
\text { multiply by }\end{array}\end{array}$ & U.S. unit & SI unit & $\begin{array}{l}\text { To convert SI to U.S., } \\
\text { multiply by }\end{array}$ \\
\hline 0.3048 & $\mathrm{ft}$ & $\mathrm{m}$ & 3.2808 \\
0.0929 & $\mathrm{ft}^{2}$ & $\mathrm{~m}^{2}$ & 10.7639 \\
2.54 & inch(es) & $\mathrm{cm}$ & 0.3937 \\
0.4536 & $\mathrm{lb}$ & $\mathrm{kg}$ & 2.2046 \\
1.4882 & $\mathrm{lb} / \mathrm{ft}$ & $\mathrm{kg} \cdot \mathrm{m}^{-1}$ & 0.6720 \\
4.8824 & $\mathrm{lb} / \mathrm{ft}^{2}$ & $\mathrm{~kg} \cdot \mathrm{m}^{-2}$ & 0.2048 \\
0.0254 & $\mathrm{mil}$ & $\mathrm{mm}$ & 39.3701 \\
0.4470 & $\mathrm{mph}$ & $\mathrm{m} \cdot \mathrm{s}^{-1}$ & 2.2369 \\
$\left({ }^{\circ} \mathrm{F}-32\right) \div 1.8$ & ${ }^{\circ} \mathrm{F}$ & ${ }^{\circ} \mathrm{C}$ & $\left(1.8 \times{ }^{\circ} \mathrm{C}\right)+32$
\end{tabular}


To achieve the simplicity of the structure, there are no permanent footings or foundations used with high tunnels. Limited footing capacity is provided by a 1.5 - to 2 inch-diameter pipe forced 18 to 24 inches deep into the ground at each metal pipe or steel tube of the greenhouse frame. The footings in the soil provide resistance to "uplift" caused by winds on the tunnel covering and framework. The tunnel framework must be rigidly attached for a secure connection to the footing pipe, as the uplift force for an 80 mph wind is $16 \mathrm{lb} / \mathrm{ft}^{2}$ or $220 \mathrm{lb} / \mathrm{ft}$ (linear) of a 14-ft-span tunnel. Therefore, each footing spaced at $4 \mathrm{ft}$ apart must be able to restrain $880 \mathrm{lb}$ of uplift force (Aldrich and Bartok, 1994) (Fig. 2).

Roof shape will affect strength, resistance to load failure, and solar radiation transmission of the tunnel structure; therefore, the roof curvature and slope are important (Fig. 1). Small radius bends of the pipe or tubing framework, which are unsupported, should be avoided. The radius of curvature of these bends, which are located at the roof ridge, and at each sidewall-to-roof transition should be no less than $2 \mathrm{ft}$. This can be the weakest point of the structure. Roof slope, which is the angle of the roof relative to the horizontal, should be greater than $10^{\circ}$ and is typically $20^{\circ}$ to $30^{\circ}$. This improves solar radiation transmission, especially above $35^{\circ} \mathrm{N}$ or below $35^{\circ} \mathrm{S}$ latitude, and is especially important if snow load occurs. Any unheated structure such as a high tunnel that can accumulate snow on its roof is vulnerable to damage by snow load. This can be resolved if the tunnel cover is removed after the final harvest and before the onset of winter storms. Condensation dripping onto the crop can be reduced by having a roof slope greater than $25^{\circ}$, as it allows for the water vapor from crop transpiration condensing on the roof to flow downward toward the sidewall, and not to form droplets that fall directly onto the crop. Thus flatshaped roofs should be avoided as they reduce the strength of structure (small radius of curvature), reduce solar radiation transmission (poor sun angle), and increase condensation dripping (small roof slope).

The compass orientation for a single-span, ground-to-ground tun-

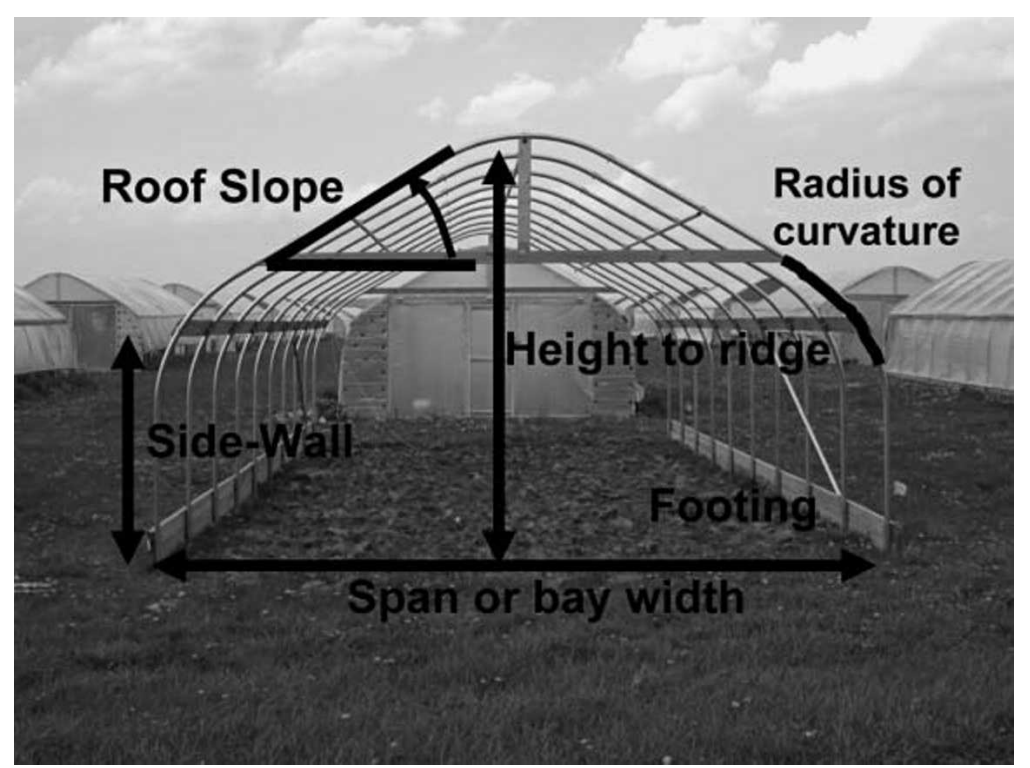

Fig. 1. High tunnel "ground-to-ground" structural framework (end view, without cover) indicating the sidewalls, the height to ridge, span width, roof slope, radius of curvature, and location of the footings (Center for Plasticulture, 2008).

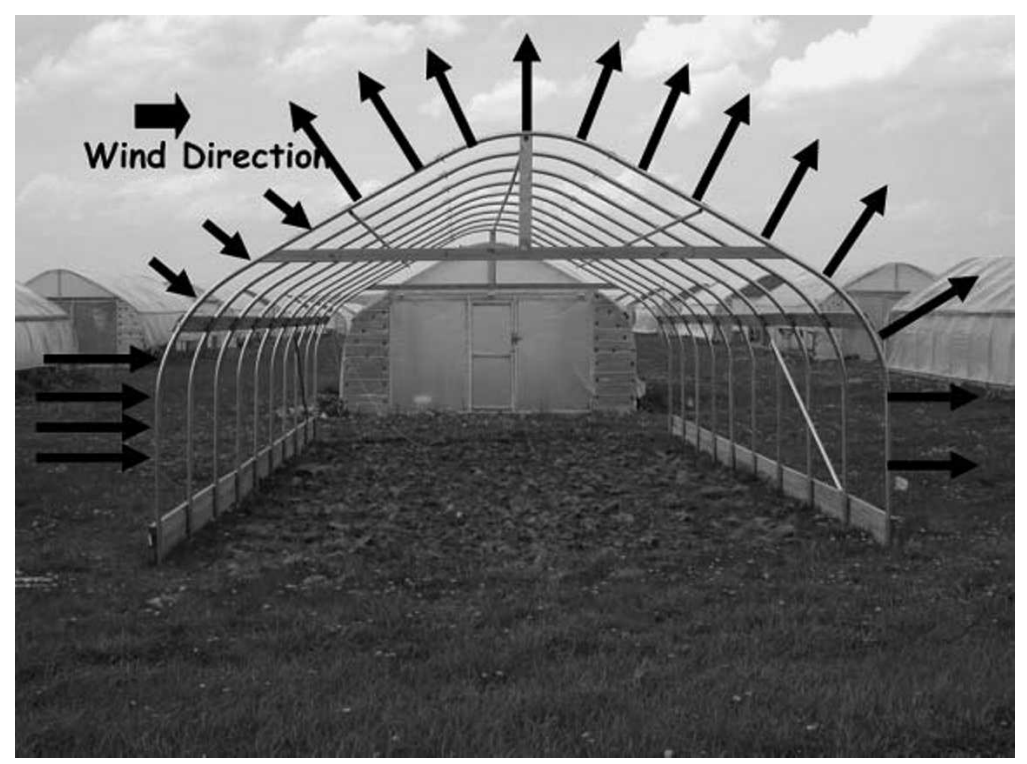

Fig. 2. High tunnel structure indicating the wind loading (inward as positive pressure, and outward as negative pressure) for the wind direction as shown (Center for Plasticulture, 2008).

nel structure should be with its ridge oriented east to west. This provides a large south-facing sidewall and roof section area, which improves solar radiation transmission compared to a north to south orientation, especially during the low sun angle of the fall, winter, and spring seasons. A multispan, gutter-connected tunnel should be oriented with ridges north to south to improve uniformity of radiation throughout the day, and reduce the fixed shadows from the overhead structure if oriented east to west. However, the distribution of solar radiation within the crop may be nonuniform, especially with multiple rows of tall crops, aligned with the east to west ridge. Shading from adjacent southern rows will occur.

The most common tunnel glazing or covering material is polyethylene (PE) film. It is the least expensive glazing, with a low initial cost, and is reliable even with only a single (as opposed to double) layer. 
Manufactured in large sheets, with widths up to $50 \mathrm{ft}$ and lengths of $200 \mathrm{ft}$ or more, PE film can provide ease of installation with continuous cover, as well as low air infiltration rates and subsequent high air humidity, but effective energy conservation. The high humidity will reduce plant transpiration, which influences growth and development. The free moisture from water vapor condensation on the PE and subsequent wetting of the crop from dripping can be a major concern for crop disease management (Both et al., 2007; Giacomelli and Roberts, 1993). Attention to structural design and dimensions to enhance natural ventilation are important to help reduce air humidity. As the distance increases from the center of the structure to the nearest ventilation opening (end wall with ventilation opening), the potential for adequate air moisture removal decreases.

The PE is attached to the singlespan, ground-to-ground tunnel frame with continuous connection at the top of each sidewall, and then spans across the entire roof section (Lamont et al., 2002). Slightly below this location, a second connection is provided for the attachment of each sidewall PE film section that will span from the top of the sidewall to the ground. This film can be detachable from the ground location so that it can be raised to provide the sidewall openings for ventilation. Attachment of the PE to the framework of the tunnel requires consideration of the security and the ease of attachment. The investment in aluminum extrusion attachment devices for the plastic film will overcome the concerns for the security of the attachment and will reduce the labor cost for covering and uncovering the tunnel. Less expensive attachments, such as nailing wooden slats onto the sidewall hip board, have traditionally been used with good success. PE attachment to a multispan, gutter-connected tunnel frame is similar for the end walls as described above. The PE is attached to the gutters on each internal roof span and is occasionally tied down directly to the structure by a rope lacing procedure.

The useful life of a newly installed PE film is from 2 to 4 years. It is weakened by ultraviolet solar radiation, high air temperature (in- cluding contact on the metal pipe greenhouse structure), air pollutants, and chemicals used for pest control (Giacomelli and Roberts, 1993). The season average solar radiation transmission, measured as photosynthetically active radiation $(P A R)$, waveband for a single-layer PE covered tunnel was 74\% (Reiss et al., 2004). Solar radiation transmission diminishes from solar chemical and thermal degradation, dust, and air pollution. Giacomelli et al. (1990), determined that after 4 years, the $P A R$ transmission through $\mathrm{PE}$ was reduced by $7 \%$.

Agricultural-quality PE film manufacturers incorporate ultraviolet radiation stabilizers to extend PE film life. Specialized PE films are now manufactured for improved tunnel system performance. These include infrared radiation absorbency for night heat savings; an antidrip film surface for reducing droplet formation and enhancing sheet flow of water vapor condensate; and selective solar radiation transmission properties to improve plant morphology.

\section{Environmental control}

Modification of the aerial environment for a single-span, groundto-ground high tunnel consists of opening the sidewalls and/or end walls for natural ventilation by the wind. It is the only air temperature reduction procedure in the high tunnel system, unless a semi-opaque shadecloth is added on top of the $\mathrm{PE}$ cover. This may reduce the inside air temperature a few degrees, but it will also reduce inside solar radiation intensity. Sidewall ventilation is completed by manual control, requiring the operator to roll up (or down) by hand the plastic film of the sidewalls. Manual operation severely limits the precision and the responsiveness of air temperature control, as a person must be present to respond to frequent changes in ventilation needs and then be able to complete a change for the entire number of tunnels that are in production. Automated control to roll the sidewall film covers up or down is available, but it requires electric power and a control system, including a mechanical actuator (motor), a sensor, and additional sidewall hardware. The cost is significantly increased, while the temporary nature, short-term yearly usage, and simplicity of the tunnel system may be lost.

Daytime cooling by natural ventilation with the wind from sidewall and/or end wall openings will create an inside air temperature that, at best, will approach the value of the outside air temperature. Once the warm season daytime outside air temperature exceeds the maximum desired inside air temperature, the plants must tolerate above-optimum air temperatures. Without a source for nighttime air heating or an internal heat curtain, the inside air temperature will about equal the outside air temperature, after sunset (Both et al., 2007). Therefore, knowing the historical average daytime maximum and nighttime minimum air temperatures will determine the approximate practical season extension application for any given location.

From Both et al. (2007), the nighttime air temperature in a single-span high tunnel $5.2 \times 11 \mathrm{~m}$ during the spring season (April and May) in New Jersey was, on the average, $0.9^{\circ} \mathrm{C}$ greater than outside. When using an internal nighttime heat curtain as an energy conservation practice (not typical in a high tunnel), an average $2.3^{\circ} \mathrm{C}$ greater air temperature than outside was obtained. The tunnel system for these tests consisted of 4-year, single-layer, no-drip, IRblocking 6-mil PE film cover and an energy curtain, which provided $15 \%$ to $20 \%$ shading and $50 \%$ energy savings according to its published properties. The curtain was mounted horizontally above the crop and was manually deployed or retracted to cover or uncover the crop twice each day. Row covers made of plastic films are sometimes used on the crops within the high tunnel to add an additional layer of insulation for environmental modification.

Modification of the root-zone environment within high tunnels consists of enhancing soil temperature and soil moisture. Within the same New Jersey high tunnel system described above, the nighttime soil temperature during the April/May period was, on average, $6.7^{\circ} \mathrm{C}$ greater than outside and $7.2^{\circ} \mathrm{C}$ greater than outside when the energy curtain was used.

Water delivery is provided by a pressurized potable water source and is distributed through a microirrigation 
system. The drip irrigation emitters uniformly distribute water to the base of each plant within the rows. The precision and dependability of current microirrigation systems provide a highly effective and efficient soil and plant root-zone watering system. If soil fertility supplementation is required, nutrition can also be provided by injector devices added to the microirrigation system. Water quality of the irrigation source should be tested.

Labor costs will include construction and operation labor for the high tunnel crop production system. Construction of the high tunnels requires methodical synthesis of subsections from component parts and then connection of subsections to establish the tunnel framework. No complex machinery, equipment, or tools are required, nor is exceptional skilled labor needed, thereby keeping construction labor costs to a minimum. Labor requirements for operations of high tunnels include crop maintenance and high tunnel system maintenance tasks. Crop tasks are similar for the same crop in field production, with exception that harvesting will be more consistent and plants will have higher yields. Increased growth and a more rapid development rate of the crop compared with field production require daily attention to monitor for plant needs and pests. High tunnel structural maintenance tasks include monitoring the structure and $\mathrm{PE}$ film for damage and repairing it as needed.

\section{Literature cited}

Aldrich, R.A. and J.W. Bartok. 1994. Greenhouse engineering NRAES-33. Natural Resource, Agriculture and Engineering Service, Cooperative Extension, Ithaca, NY.

Both, A.J., E. Reiss, J.F. Sudal, K.E. Holmstrom, C.A. Wyenandt, W.L. Kline, and S.A. Garrison. 2007. Evaluation of a manual energy curtain for tomato production in high tunnels. HortTechnology 17(4):467-472.
Center for Plasticulture. 2008. High tunnel image gallery. 16 July 2008 . $<$ http://plasticulture.cas.psu.edu/IMAGES/ tunnel $/>$.

Costa, P. and G.A. Giacomelli. 2005. Ensuring success: Protected horticulture. Productivity based on levels of technology. The ABCs of greenhouse production technological considerations. Productores de Hortalizas 14(2):48-53.

Giacomelli, G.A. and W.J. Roberts. 1993. Greenhouse glazing systems. HortTechnology 3(1):50-58.

Giacomelli, G.A., K.C. Ting, and W. Fang. 1990. Wavelength specific transmission of polyethylene film greenhouse glazing. Proc. 22nd Natl. Agr. Plastics Congr. p. 129-134.

Lamont, W.J., M.R. McGann, M.D. Orzolek, N. Mbugua, B. Dye, and D. Reese. 2002. Design and construction of the Penn State high tunnel. HortTechnology 12(3):447-453.

Reiss, E., A.J. Both, S. Garrison, W.L. Kline, and J.F. Sudal. 2004. Season extension for tomato production using high tunnels. Acta Hort. 659:153-160. 